\title{
Bilateral Fusion of Mandibular Second Molars with Supernumerary Teeth: Case Report
}

\author{
Eduardo NUNES ${ }^{1}$ \\ Ivaldo Gomes de MORAES ${ }^{2}$ \\ Paulo Márcio de Oliveira NOVAES ${ }^{3}$ \\ Simone Maria Galvão de SOUSA ${ }^{4}$ \\ ${ }^{1}$ Department of Endodontics, Pontificial Catholic University, Belo Horizonte, MG, Brazil \\ ${ }^{2}$ Department of Endodontics, Bauru Dental School, Bauru, SP, Brazil \\ ${ }^{3}$ Private Endodontic Practice, Belo Horizonte, MG, Brazil \\ ${ }^{4}$ Department of Oral Pathology, Faculty of Dentistry, University of Sacred Heart, Bauru, SP, Brazil
}

\begin{abstract}
Fusion is a developmental anomaly characterized by the union of two adjacent teeth. In this article we report a rare case of bilateral fusion of permanent mandibular second molars with supernumerary teeth. The rarity with which this entity appears, along with its complex characteristics, often make it difficult to treat. The endodontic management of one tooth is described, as well as the successful treatment of a periradicular lesion.
\end{abstract}

Key Words: dental anomaly, fusion, supernumerary tooth, endodontic treatment.

\section{INTRODUCTION}

Fusion is commonly identified as the union of two distinct dental sprouts which occurs in any stage of the dental organ. They are joined by the dentine; pulp chambers and canals may be linked or separated depending on the developmental stage when the union occurs. This process involves epithelial and mesenchymal germ layers resulting in irregular tooth morphology (1). Moreover, the number of teeth in the dental arch is less than normal. A review of the literature reveals great difficulty in correctly differentiating fusion and gemination. For a differential diagnosis between these anomalies, the dentist must carry out a highly judicious radiographic and clinical examination.

The aetiology of fusion is still unknown, but the influence of pressure or physical forces producing close contact between two developing teeth has been reported as one possible cause (2). Genetic predisposition and racial differences have also been reported as contributing factors.

This anatomic irregularity occurs more often in the deciduous than in the permanent dentition. Only a few cases of fusion involving molar and premolar teeth have been reported (3-5) whereas, in both dentitions, the prevalence is higher in the anterior region (6-9). Cases of bilateral fusion are less frequent than unilateral fusion (6). Turell and Zmener (3) described a case of fusion involving a mandibular third molar and fourth molar (distomolar). Unfortunately, most of these fusions require surgical removal because of their abnormal morphology and excessive mesiodistal width, which cause problems with spacing, alignment and function $(6,8)$. In the anterior region this anomaly also causes an unpleasant aesthetic tooth shape due to the irregular morphology. These teeth also tend to be greatly predisposed to caries and periodontal disease and, in some cases, endodontic treatment is very complicated $(7,10)$.

Fusion can occur between teeth of the same dentition or mixed dentitions, and between normal and supernumerary teeth $(3,7-9,11,12)$. In these cases, the number of teeth in the dental arch is also normal and differentiation from gemination is clinically difficult or impossible. A diagnostic consideration, but not a set rule, is that supernumerary teeth are often slightly aberrant and present a cone-shaped clinical appear- 
ance. Thus, fusion between a supernumerary normal tooth will generally show differences in the two halves of the joined crown. However, in gemination cases the two halves of the joined crown are commonly mirror images.

Fused teeth usually present asymptomatically. In fact, the co-operation of practitioners with expertise in multiple areas of dentistry is important to create or achieve functional and esthetic success in these cases. Several treatment methods have been described in the literature with respect to the different types and morphological variations of fused teeth, including endodontic, restorative, surgical, periodontal and/or orthodontic treatment $(3-9,12)$.

This paper reports a rare case of bilateral fusion of the mandibular permanent second molars with supernumerary elements, in which one was successfully treated with nonsurgical endodontic therapy. The other required no treatment.

\section{CASEREPORT}

An 18-year-old white female was seen at the Dental Clinic for routine dental care because of a sinus tract on the mandibular right region. The patient did not complain of previous painful symptoms in that region and her medical and dental histories were unremarkable. Clinical examination revealed the presence of an irregular bilateral morphology of the permanent mandibular second molars. The aspect of the dental elements suggested the union of a supernumerary tooth crown with the mesial crown of these molars. In addition, increased mesio-distal crown width and distinct devel-

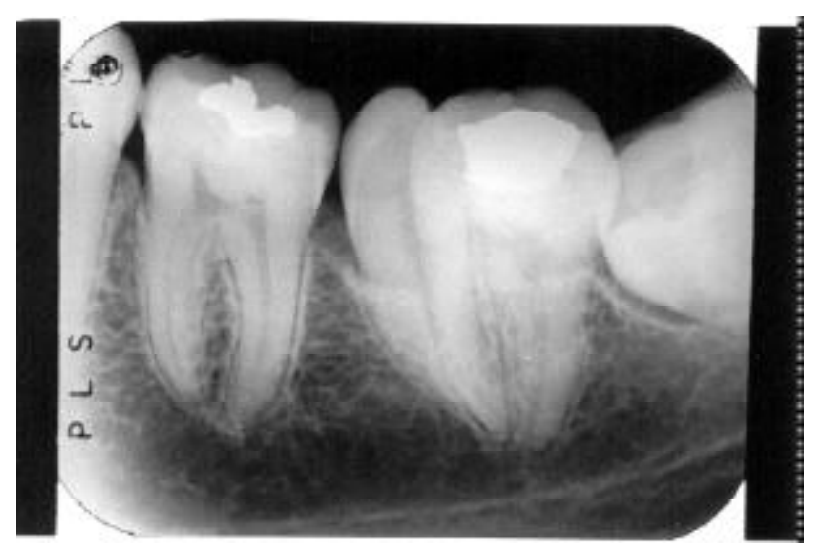

opmental occluso-gingival grooves on the labial and lingual surfaces were noticed. The remaining maxillary and mandibular permanent teeth were normal in shape and no permanent tooth was absent.

The presence of the sinus tract was confirmed on the labial mucous membrane region of tooth 47 . Tooth 47 was caries free with no restoration. It was out of alignment, and apparently in traumatic occlusion. Teeth 37 and 47 were found to be free from periodontal disease. The right second molar (47) did not respond to pulp testing and was tender to percussion, whereas the left second molar (37) responded within normal limits. Radiographic examination showed the union of a supernumerary tooth with the second permanent molar, suggesting bilateral fusion and presence of an extensive periradicular lesion associated only with tooth 47 (Figure 1). No connection between the fused tooth root canal systems could be detected radiographically.

The sinus tract was traced with an FM guttapercha cone to the lesion. The diagnosis of tooth 47 was necrotic pulp associated with suppurative apical periradicular lesion. After administering inferior alveolar nerve local anesthesia, two separate access preparations were made in the occlusal surface of each of the clinical crowns in tooth 47 (Figure 2). Under rubber dam isolation, the occlusal access was finished, followed by copious irrigation with $1 \%$ sodium hypochlorite and careful localization of canals.

Four canal openings were found, three mesially and one distally. Following working length determination (Figure 3), the root canals were instrumented with a step-back technique associated with oscillatory movements. The root canals were wide and the final apical

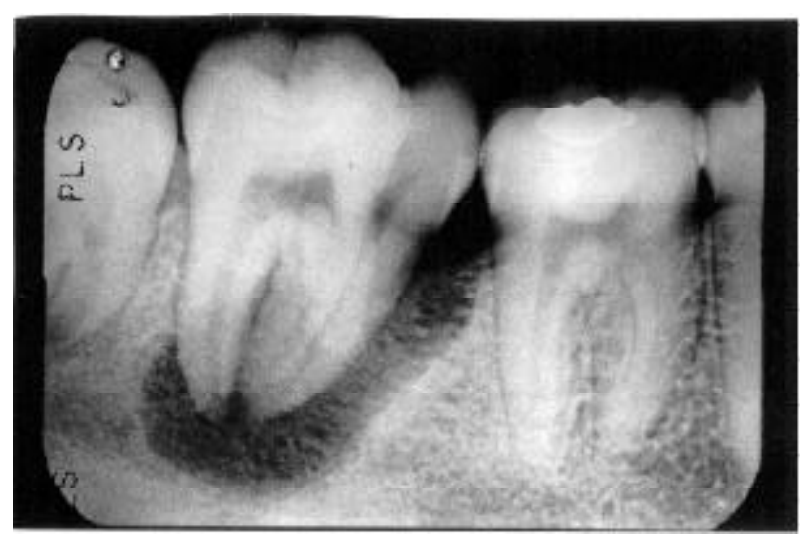

Figure 1. Preoperative radiograph of the fused mandibular second molars and supernumerary teeth. The right second molar presents an extensive periapical radiolucent area (right panel). 
files in the distal, mesiobuccal, mesiolingual, and the supernumerary canals were \#60 K file, \#50 K file, \#45 $\mathrm{K}$ file and \#45 K file, respectively (Dentsply, Milford, DE). All canals were stepped back to \#80 K file and \#2, 3, 4 Gates-Glidden drills were used. A \#10 stainlesssteel file was used for canal length patency recapitulation. The mesiolingual canal communicated with the supernumerary root canal in the apical third. Irrigation with $1 \%$ sodium hypochlorite was used throughout instrumentation. After drying the root canals with paper points, calcium hydroxide paste with propylene glycol was placed in the canals with a lentulo spiral.

After 30 days the patient returned for continuation of root canal therapy. At this time, the initial healing process of the tract could already be observed. The tooth was re-opened, the calcium hydroxide removed and the root canals dried and filled by lateral condensation of gutta-percha points (Dentsply, Petrópolis, RJ) and Endofill sealer (Dentsply). The

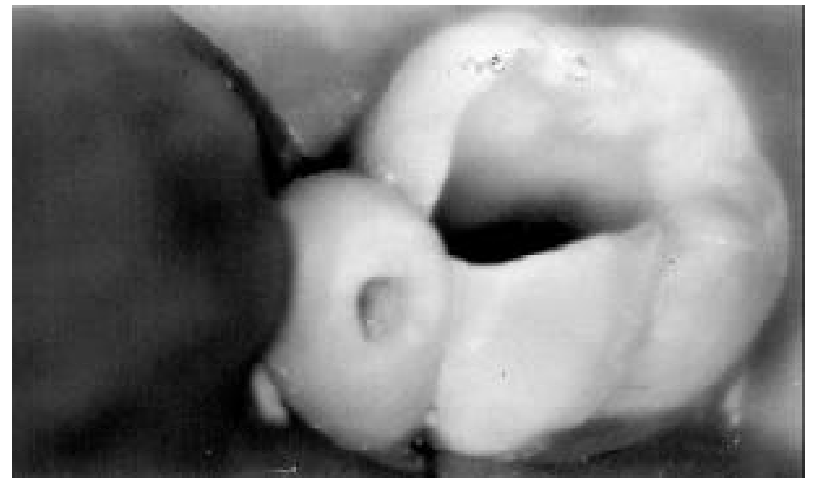

Figure 2. Intraoral view of access cavities occlusally in tooth and in extra cusp.

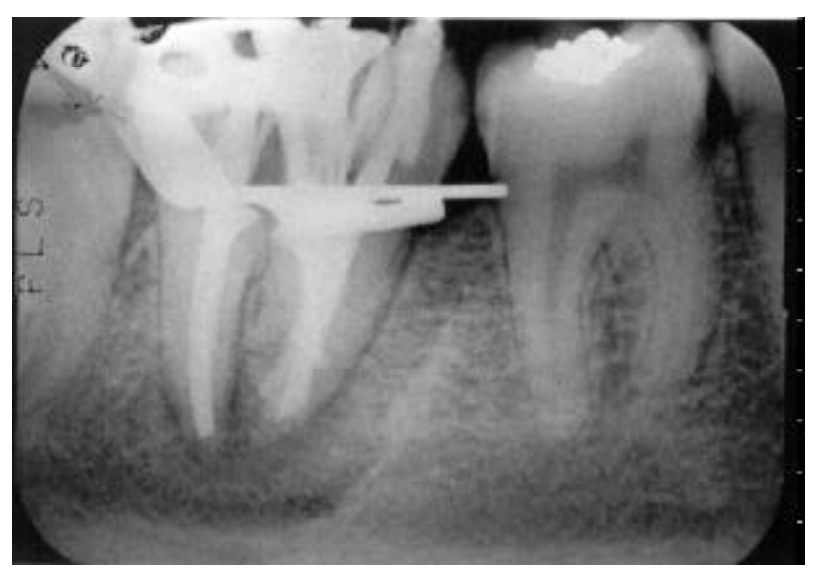

Figure 4. Lateral condensation radiograph. Note that periapical repair has progressed well. condensation radiograph showed the repair process of both lateral pathology along the mesial roots and periradicular area was progressing well (Figure 4). The teeth were restored with resin and the patient was encouraged to practice strict oral hygiene in order to prevent periodontal disease due to the buccal and lingual grooves.

After a 3-month period, the patient returned for evaluation. The tooth remained asymptomatic and a periapical radiograph revealed reduction of the periradicular radiolucency, suggesting initially successful endodontic treatment (Figure 5). The left molar required no treatment because no caries or periodontal disease were present.

\section{DISCUSSION}

The terminology dental fusion and gemination are used to define two different morphological dental

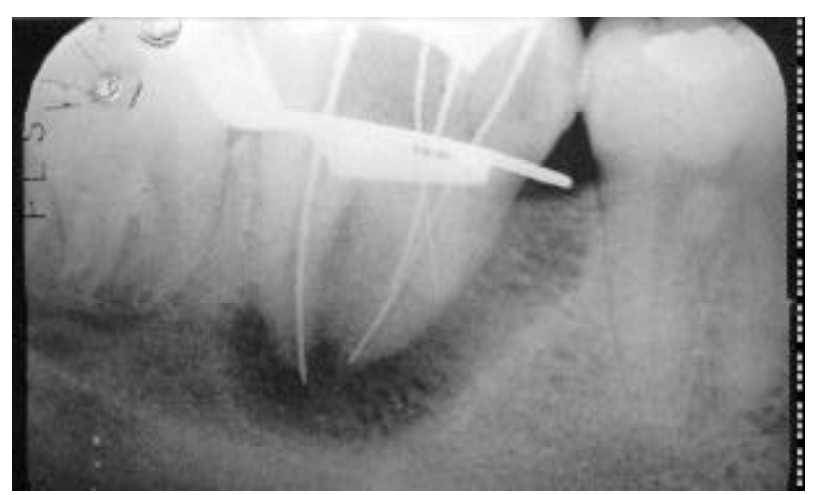

Figure 3. Radiograph with instruments in root canals for working length determination.

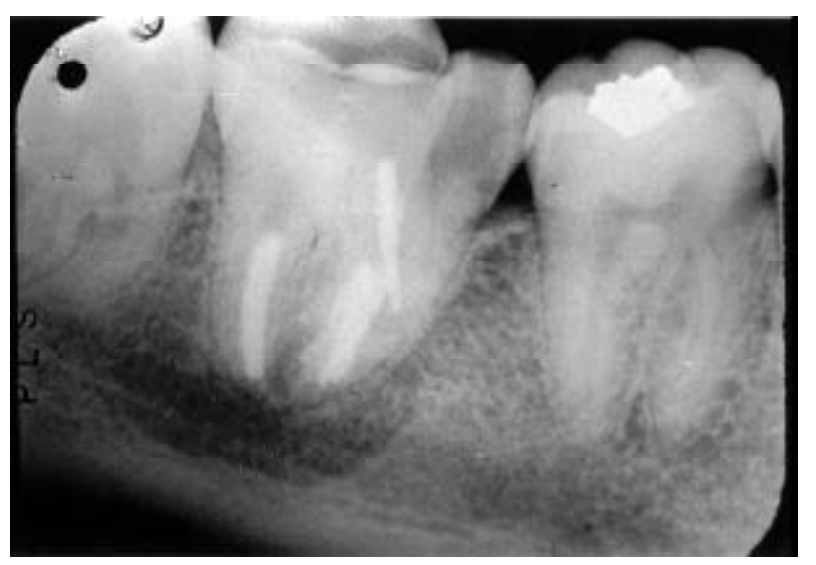

Figure 5. Three-month recall radiograph showing the repair of the periapical and lateral root areas. 
anomalies, characterized by the formation of a clinically wide tooth. Despite the considerable number of cases reported in the literature, the differential diagnosis between these abnormalities is difficult. Case history and clinical and radiographic examinations can provide the information required for the diagnosis of such abnormalities. After a judicious evaluation of all information, we can report that this case represents bilateral fusion of second mandibular molars with supernumerary teeth. This case report is very similar to the one reported by Beltes and Huang (4), except for the bilateral involvement.

Teeth with this abnormality are unaesthetic due to their irregular morphology. They also present a high predisposition to caries and periodontal disease, and spacing problems. The main periodontal complication in fusion cases occurs due to the presence of fissures or grooves in the union between the teeth involved. If these defects are very deep and extend subgingivally, the possibility of bacterial plaque accumulation in this area is quite high. Strict oral hygiene is imperative to maintain periodontal health. Furthermore, fusion may have an adverse effect on occlusion, causing deviation and, sometimes, delaying the eruption of other teeth. In this case, the traumatic occlusion resulting from tooth 47 being out of alignment may be the reason for the pulp necrosis and periradicular lesion.

Efforts must be directed to understand the root canal anatomy in order to avoid treatment complications. Despite the fact that surgical therapy may be necessary in some cases, a thorough knowledge of the complexity of root canal morphology in addition to adequate operative procedures appear to be the main requirements for successful endodontic treatment of these dental abnormalities. Difficult cases include a wide spectrum of problems. The best way to manage these difficult cases depends on a number of factors including the knowledge and technical skills of the practitioner.

In some instances, one of the first procedures of endodontic therapy, rubber dam isolation, may be complicated due to the anatomical size and shape of the crown. Locating canals during access preparation can be difficult. Mesial and/or distal radiographic projections can give more information about morphological features and the relationship between the canals, making the interpretation of structures easier.

Intracanal medicament has been considered an important step in successful endodontic therapy. Calcium hydroxide is recommended as a long-term medicament between appointments and in pulp necrosis associated with periradicular periodontitis because of its antibacterial properties. This medicament has also been shown to change the environment in the dentin and bone to a more alkaline $\mathrm{pH}$, which has been postulated to slow down the action of the resorptive cells and promote hard tissue formation and repair (13). Nerwich et al. (13) reported that calcium hydroxide used as a root canal dressing significantly increased the $\mathrm{pH}$ in the apical region only after 2-3 weeks. This justifies the choice of the longer period (30 days) used in this case for the efficacy of the paste, which may have contributed to the significant reduction of the periradicular lesion.

In conclusion, different cases require a variety of knowledge about alternative operative techniques and abilities. A multidisciplinary approach with different practitioners working together can contribute to the success of a treatment plan.

\section{RESUMO}

Nunes E, de Moraes IG, Novaes PMO, de Sousa SMG. Fusão bilateral dos segundos molares inferiores com dente supranumerário: relato de caso. Braz Dent J 2002;13(2):137141.

A fusão é uma anomalia de desenvolvimento dental caracterizada pela união de dois dentes adjacentes. Devido a baixa frequiência desta alteração e as suas características morfológicas complexa o tratamento, quando indicado, torna-se muitas vezes difícil. Neste artigo iremos relatar um caso raro de fusão bilateral entre os segundos molares inferiores com dentes supranumerários.

Unitermos: anomalia dental, fusão, dente supranumerário, tratamento endodôntico.

\section{REFERENCES}

1. Tannenbaum AK, Alling EE. Anomalous tooth development: case reports of gemination and twinning. Oral Surg Oral Med Oral Pathol 1963;16:883-888.

2. Shafer WG, Hine MK, Levy BM. A textbook of pathology. $4^{\text {th }}$ ed. Philadelphia: WB Saunders Company, 1983.

3. Turell IL, Zmener O. Endodontic therapy in a fused mandibular molar. J Endod 1999;25:208-209.

4. Beltes P, Huang G. Endodontic treatment of an unusual mandibular second molar. Endod Dent Traumatol 1997;13:96-98.

5. Caceda JH, Creath CJ, Thomas JP, Thornton JB. Unilateral fusion of primary molars with the presence of a succedaneous supernumerary tooth: case report. Paediat Dent 1994;16:53-55.

6. Delany GM, Goldblatt LI. Fused teeth: a multidisciplinary ap- 
proach to treatment. J Amer Dent Assoc 1981;103:732-734.

7. Peyrano A, Zmener O. Endodontic management of mandibu-

lar lateral incisor fused with supernumerary tooth. Endod Dent Traumatol 1995;11:196-198.

8. Hülsmann M, Bahr R, Grohmann U. Hemisection and vita treatment of a fused tooth - literature review and case report. Endod Dent Traumatol 1997;13:253-258.

9. Velasco LF de, Araujo FB, Ferreira ES, Velasco LE. Esthetic and functional treatment of a fused permanent tooth: a case report. Quintessence Int 1997;28:677-680.

10. Pereira AJA, Fidel RAS, Fidel SR. Maxillary lateral incisor with two root canals: fusion, gemination or dens invaginatus? Braz Dent J 2000;11:141-146.

11. Camm HJ, Wood JA. Gemination, fusion and supernumerary tooth in the primary dentition: report of case. J Dent Child 1989;56:60-61

12. Spatafore CM. Endodontic treatment of fused teeth. J Endod 1992;18:628-631.

13. Nerwich A, Figdor D, Endo D, Messer HH. pH changes in root dentin over a 4-week period following root canal dressing with calcium hydroxide. J Endod 1993;19:302-306.

Accepted March 25, 2002 